\title{
The Association of Internet Addiction with Depression and Anxiety in University Students
}

\author{
Üniversite Öğrencilerinde İnternet Bağımlılı̆̆ının Depresyon ve \\ Anksiyete İle İlişkisi
}

\author{
Başak Korkmazer ${ }^{1}$, Mehmet G. Kılınçarsla ${ }^{l}$, Erkan M. Şahin ${ }^{l}$
}

\begin{abstract}
Introduction: In adolescence, tendency to risky health behaviours including internet addiction is frequent. Research on the etiology of internet addiction is at an early stage and has been associated with depression and social isolation indicatorsThe present study was conducted with the aim of investigating the association of internet addiction with depression and anxiety in university students. Method: The study was carried out as an online survey study on 28572 university students who were educated in the central campus of Çanakkale On sekiz Mart University in academic year of 2011-2012. A total of $4430(15.5 \%)$ students were reached. Of them, $3064(69,2 \%)$ answered questions about computer and internet use. In this research, which is part of a multidimensional study, the BAPINT scale was used to measure internet addiction and BAPI-K scale was used to measure depression and anxiety. Binary Logistic Regression analysis was performed following univariate tests. Results: While the mean age of the participants who responded the questions about internet use was 21,7 $\pm 3,2$ [17-63], $55,1 \%$ (1688) were female and 44,9\% (1374) were male. Of the participants, $34.6 \%$ had internet addiction according to BAPINT scale. In the regression analysis, all predictors were found to be statistically significant $\left(X^{2}=173,553 p<0,001\right)$. After independent variables were controlled, it was found that depression increases internet addiction 1,799 $(1,485-2,170 \mathrm{p}<0,05)$ fold, and anxiety increases internet addiction $1,708(1,423-2,050 \mathrm{p}<0,05)$ fold. Discussion: The rate of internet addiction in our study $(34.6 \%)$ was similar to that of the other studies conducted with university students in our country (18.9\%- 56.9\%). Internet addiction was found to be associated with mental disorders like depression and anxiety. The causality between internet addiction and mental health has not yet been fully resolved; with the widespread use of internet in all areas and communities, especially the young people take part in the risky population and it is important to consider internet addiction in the follow-up of the young people with anxiety or depression.
\end{abstract}

Key words: Internet addiction, mental health, youth

ÖZET

Amaç: Gençlik döneminde riskli sağlık davranışlarına yatkınlık sık görülmektedir ve internet bağımlılığı da bunlardan biridir. İnternet bağımlılığının etiyolojisiyle ilgili araştırmalar henüz başlangıç aşamasındadır ve boyutsal olarak ölçülen depresyon ve sosyal izolasyon göstergeleri ile ilișkilendirilmiștir. Bu araștırmada üniversite öğrencilerinde internet bağımlılığ ile depresyon ve anksiyete arasındaki ilişkiyi incelemeyi amaçladık. Yöntem: Bu çalışma Çanakkale On sekiz Mart Üniversitesi’nin merkez yerleşkesinde 2011 - 2012 eğitim yılında eğitim alan 28572 üniversite öğrencisi üzerinde online anket çalışması olarak yürütüldü. Toplamda $4430(\% 15,5)$ öğrenciye ulaşıldı. Bunların 3064'ü $(\% 69,2)$ bilgisayar ve internet kullanımı sorularını cevaplamıştı. Ç ok boyutlu bir çalışmanın parçası olan bu araştırmada 71 soruluk orijinal anket dahilinde internet bağımlılığını ölçmek için BAPiNT ölçeği; depresyon ve anksiyeteyi ölçmek için BAPİ-K ölçeği kullanıldı. Tek değişkenli testlerden sonra İkili Lojistik Regresyon analizi yapıldı. Bulgular:

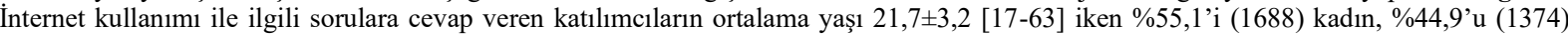
erkekti. Katılımcıların \%34,6’i BAPINT ölçeğine göre internet bağımlılığına sahipti. Regresyon analizinde tüm kestirimcileri içeren model istatistiksel olarak anlamlı bulundu $\left(\mathrm{X}^{2}=173,553 \mathrm{p}<0,001\right)$. Bağımsız değişkenler kontrol edildikten sonra internet bağımlılı̆ıını, depresyonun $1,799(1,485-2,179 \mathrm{p}<0,05)$ kat, anksiyetenin ise $1,708(1,423-2,050 \mathrm{p}<0,05)$ kat arttırdığı saptandı. Sonuç: Çalışmamızdaki internet bağımlılı̆̆ 1 oranı $(\% 34,6)$ ülkemizde üniversite öğrencileri arasında yapılmıș diğer çalıșmaların saptadı̆̆ı oranlar $(\% 18,9-\% 56,9)$ ile benzerdi. Önceki ulusal ve uluslararası çalışmalarla uyumlu olarak internet bağımlılığının depresyon ve anksiyete gibi ruhsal bozukluklarla ilişki gösterdiği saptandı. İnternet bağımlılığı ile mental sağlık arasındaki nedensellik henüz tam çözümlenememiş olup; her alan ve toplulukta internet kullanımının yaygınlaşmasıyla birlikte özellikle gençler riskli populasyonda yer almakta, anksiyete veya depresyonu olan gençlerin takibinde internet bağımlılı̆̆ının da göz önünde bulundurulması önem taşımaktadır.

Anahtar kelimeler: İnternet bağımlılı̆̆ı, akıl sağlı̆̆, gençlik

Received Date: 03.05.2019, Accepted Date: 20.09.2019

*1 ÇOMÜ Tıp Fakültesi

*Address for Correspondence / Yazıșma Adresi: COMÜ Tıp Fakültesi Eğitim Sağlık Uygulama ve Araștırma Hastanesi A Blok 2. Kat Aile Hekimliği Polikliniği, Çanakkale E-mail: basakkorkmazer@gmail.com

Korkmazer B, Kılınçarslan MG, Şahin EM. Üniversite Öğrencilerine İnternet Bağımlılığının Depresyon ve Anksiyete İle İlişkisi TJFMPC, 2019;13 (4): 548-552DOI: $10.21763 /$ tjfmpc.560204 


\section{Gİiş̧}

Gelişen dünyada iletişimi ve bilgi paylaşımını kolaylaştırmak amacıyla ortaya çıkan internet artık birçok insanın günlük hayatının ayrılmaz bir parçasıdır. Birleşmiş Milletler verilerine göre 2018 y1lı sonu itibarıyla küresel nüfusun $\% 51,2$ 'sinin internet kullandığ 1 tahmin edilmektedir. ${ }^{1}$ Ülkemiz içinse Türkiye istatistik Kurumu (TUİK) 2018 yılı Nisan ayı verilerine göre, hanelerin \%83,8'i evden internete erişim imkânına sahipken, genç yaş grubunda internet kullanım oranı \%59,6'dır. ${ }^{2}$

Geleneksel olarak bağımlılık terimi, alkol ve tütün gibi psikoaktif maddelerle ilişkilendirilmekte olmasına rağmen, internet kullanımının dahil olduğu davranışların da yakın zamanda bağımlılık yarattığı tespit edilmiştir. ${ }^{3}$

Dünya genelinde sosyal bir sorun haline gelmekte olan internet bağımlılığı genel olarak, kişinin internet kullanımını günlük hayatta olumsuz sonuçlara yol açacak biçimde kontrol edememesi şeklinde tanımlanabilir. ${ }^{4}$

İnternet bağımlılı̆̆ $1, \quad 2013 \quad$ yılında yayınlanan Mental Bozuklukların Tanısal ve Sayımsal El Kitabının Beşinci Basımı (DSM-5) sınıflandırmasında yer almamış olsa da, ilk kez, "İnternet oyun bozukluğu" şeklinde ve "ileri çalıșmalar gerektiren" bir durum olarak III. bölüme dahil edilmiştir. Etiyolojiyle ilgili araştırmalar henüz başlangıç aşamasındadır ve boyutsal olarak ölçülen depresyon ve sosyal izolasyon göstergeleri ile ilişkilendirilmektedir. ${ }^{4,5}$

Gençlik dönemi, fiziksel, sosyal ve psikolojik özelliklerde kayda değer değişiklikler ile karakterize olan hassas bir geçiş dönemidir. Ayrıca, gençler, kararları, duyguları ve davranışları üzerinde özerklik göstermeye başladığından, akranlar, aile ve toplumla ilişkiler bu dönemde farklı değişikliklere uğramaktadır. Gençlerde sosyal yetenekler genellikle psikososyal etkileşimler sırasında gelişmektedir. Sosyal biliş ve becerilerin geliștirilmesine yönelik kapsamlı bir platform olarak göz önüne alındığında, internet, gençler arasında psikososyal gelişim için yeni ve benzersiz bir kanal olduğunu kanıtlamıştır. ${ }^{6}$

Yetişkinlere kıyasla gençler sosyal paylaşım siteleri ve oyunlar gibi zaman alıcı uygulamalara daha fazla vakit ayırmaktadırlar. İnternet kullanım sürelerinin daha fazla olmasının yanı sıra, gençlik döneminde riskli sağlık davranışlarına yatkınlık sık görülmektedir ve internet bağımlılığı da bunlardan birisidir. Sağlıklı internet kullanımı, gençlerin bilgiye ulaşmasını kolaylaştırıp çeşitli becerilerini geliştirmesine katkıda bulunurken, kontrolsüz internet kullanımı ise gençlerin fiziksel, psikolojik, sosyal ve bilişsel gelişimini olumsuz yönde etkileyebilmektedir. ${ }^{7}$

$\mathrm{Bu}$ bilgiler 1şı̆̆ında araştırmamızda üniversite öğrencilerinde internet bağımlılı̆̆ depresyon ve anksiyete arasındaki ilişkiyi incelemeyi amaçladık.

\section{YÖNTEM}

$\mathrm{Bu}$ çalışma için onay ve izinler Klinik Araştırmalar Etik Kurulu'ndan ve Çanakkale On sekiz Mart Üniversitesi Rektörlüğü’nden alındı.

Çalışmamızda 2011-12 eğitim öğretim y1lında Çanakkale On sekiz Mart Üniversitesi'nde eğitim görmekte olan 28582 öğrenciye, çok boyutlu gençlik anketinin bir parçası kullanıldı. Anket, çevrimiçi şekilde, tüm öğrencilerin y1l boyunca çeşitli zamanlarda ders seçiminde ve ders notlarını öğrenmede kullandıkları otomasyon sistemi aracılığıyla uygulandı. İlk olarak katılımcılara çalışma hakkında bilgi verilerek daha sonra onayları istendi. Onay vermiş olan katılımcılardan anket sorularını isimsiz olarak doldurmaları istendi. Anketi tamamlarken katılımcılar cevaplamak istemedikleri soruları atlayabildiler. Ankete katılım oranlarını artırmak için bildirim öğretim yılı boyunca tekrarlandı. Orijinal anket 71 soru içermekteydi, ancak bu çalışmada 13 tanesi amacımız doğrultusunda değerlendirildi. İnternet bağımlılığ 1 , depresif belirtiler ve anksiyete BAPI ölçek kılavuzları ile ölçüldü. ${ }^{8}$

Benzer çalışmalar örnek alınarak evrenin en az \%10'una ulaşmak amaçland. Toplamda $4430 \quad(\% 15,5)$ öğrenciye ulaşıldı. Bunların 3064'ü $(\% 69,2)$ BAPINT internet bağımlılı̆̆ı tarama ölçeğini cevaplamıştı.

Veriler istatistiksel olarak IBM SPSS Statistics 20 yazılımı kullanılarak analiz edildi ve sonuçları tanımlayıcı istatistikler, sürekli değişkenler için ortalama \pm standart sapma, kategorik değişkenler için frekans ve yüzde olarak ifade edildi; tek değişkenli analizler Ki-Kare testi kullanılarak yapıldı. İnternet bağımlılı̆̆ı ile ilişkili faktörleri değerlendirmek için İkili Lojistik Regresyon Analizinin "Hiyerarşik" modeli kullanıldı. Tüm bağımsız değişkenler bu modele dahil edildi. İlk olarak, genel özellikler, daha sonra ruh sağlığı değişkenleri modele sırasıyla eklendi. Tüm analizler iki yönlü $p$ değerleri için incelendi ve anlamlılık düzeyi $\mathrm{p}<0,05$ olarak kabul edildi.

\section{BULGULAR}

Katılımcıların ortalama yaşı 21,6 $\pm 3,2$ [17-63] idi, 1688'i $(\% 55,1)$ kadın, 1374'ü $(\% 44,9)$ erkek idi. 
Öğrencilerin $1621^{\prime} i(\% 52,9)$ fakültelerde, 1441'i $(\% 47,1)$ yüksek okullarda eğitim görmekteydi. Öğrencilerin $1022 \quad(\% 33,4)$ 'sindeakademik y1l kayb1 varken 2042'sinde $(\% 66,6)$ ise y1l kayb1 yoktu.

BAPINT tarama formunu oluşturan "İnternet kullanım süresi" ile "internet kullanımının kişinin hayatında soruna yol açma" sorularının toplam skoru 3,5 puan için kesme noktasında ayrıştırıld1. ${ }^{9}$ Öğrencilerin BAPINT ortalama puanı $3,0 \pm 1,7[0-8]$ olarak tespit edildi.

BAPINT ölçeğine göre katılımcıların 1061'inde $(\% 34,6)$ internet bağımlılığ1 mevcuttu. İnternet bağımlılığı hakkında cinsiyetler arasında anlamlı fark yokken $p=0,058$ ) internet bağımlılığ1 açısından fakültede eğitim görüyor olma yönünde anlamlı fark mevcuttu $\mathrm{p}<0,001)$. Aynı zamanda akademik yıl kaybınınolması da internet bağımlılı̆̆1 açısından anlamlı fark göstermekteydi $\mathrm{p}=0,004$ ).
BAPI-K depresyon tarama ölçeğini cevaplayan öğrencilerin 881 'inde $(\% 28,2)$ depresyon mevcuttu. Depresyon açısından cinsiyetler arasında erkek cinsiyet yönünde anlamlı fark mevcuttu $\mathrm{p}<0,001$ ). Fakülte ve yüksek okulda eğitim görmekte olan ögrenciler arasında depresyon açısından anlamlı fark yokken $\mathrm{p}=0,966$ ), akademik yıl kaybı varlı̆̆ 1 depresyon açısından anlamlı fark göstermekteydi $\mathrm{p}<0,001)$.

BAPI-K anksiyete tarama ölçeğini cevaplayan öğrencilerin 1032'sinde $(\% 33,1)$ anksiyete mevcuttu. Anksiyete hakkında cinsiyetler arasında $\mathrm{p}=0,001$ ); fakültede eğitim görüyor olma ve akademik yıl kaybı varlığı anksiyete açısından anlamlı fark göstermekteydi (sırasıla $\mathrm{p}=0,006$ ve $\mathrm{p}<0,001)$. Tüm tek değişkenli analizler Tablo 1'de gösterilmektedir.

\begin{tabular}{|c|c|c|c|}
\hline \multicolumn{4}{|l|}{ İnternet bağımlılığı } \\
\hline \multirow[t]{2}{*}{ Cinsiyet } & Kadın & $559(\% 33,1)$ & \multirow[t]{2}{*}{$\mathrm{p}=0,058 *$} \\
\hline & Erkek & $500(\% 36,4)$ & \\
\hline \multirow[t]{2}{*}{ Eğitim } & Fakülte & $629(\% 38,8)$ & \multirow[t]{2}{*}{$\mathrm{p}<0,001 *$} \\
\hline & Yükse okul & $430(\% 29,8)$ & \\
\hline \multirow[t]{2}{*}{ Akademik yıl kaybı } & Var & $(\% 38,2)$ & \multirow[t]{2}{*}{$\mathrm{p}=0,004 *$} \\
\hline & Yok & $(\% 32,9)$ & \\
\hline \multicolumn{4}{|l|}{ Depresyon } \\
\hline \multirow[t]{2}{*}{ Cinsiyet } & Kadın & $356(\% 22,0)$ & \multirow{2}{*}{$\mathrm{p}<0,001 *$} \\
\hline & Erkek & $493(\% 36,8)$ & \\
\hline \multirow{2}{*}{ Eğitim } & Fakülte & $449(\% 28,7)$ & \multirow[t]{2}{*}{$\mathrm{p}=0,966^{*}$} \\
\hline & Yüksekokul & $400(\% 28,7)$ & \\
\hline \multirow[t]{2}{*}{ Akademik yıl kaybı } & Var & $357(\% 36,1)$ & \multirow{2}{*}{$\mathrm{p}<0,001 *$} \\
\hline & Yok & $492(\% 25,0)$ & \\
\hline \multicolumn{4}{|l|}{ Anksiyete } \\
\hline \multirow[t]{2}{*}{ Cinsiyet } & Kadın & $499(\% 30,9)$ & \multirow[t]{2}{*}{$\mathrm{p}=0,001^{*}$} \\
\hline & Erkek & $491(\% 36,8)$ & \\
\hline \multirow[t]{2}{*}{ Eğitim } & Fakülte & $558(\% 35,9)$ & \multirow[t]{2}{*}{$\mathrm{p}=0,006^{*}$} \\
\hline & Yüksekokul & $432(\% 31,0)$ & \\
\hline \multirow[t]{2}{*}{ Akademik yıl kaybı } & Var & $398(\% 40,5)$ & \multirow[t]{2}{*}{$\mathrm{p}<0,001 *$} \\
\hline & Yok & $592(\% 30,1)$ & \\
\hline
\end{tabular}

Analizin son aşamasında, internet bağımlılı̆̆ını öngördüren değişkenleri belirleyebilmek amacıyla hiyerarşik regresyon analizi yapıldı. Yaş, cinsiyet, eğitim ve akademik yıl kaybını içeren bağımsız değişkenlerin etkisi istatistiksel olarak elimine edildikten sonra depresyon ve anksiyete ile internet bağımlılığı arasındaki ilişki incelendi. Model analizine göre depresyonu olanlarda olmayanlara kıyasla internet bağımlılığı görülme riski 1,79 kat artarken; anksiyetesi olanlarda olmayanlara kıyasla internet bağımlılığı görülme riskinde 1,70 kat artış görülmekteydi. Regresyon modellerinin özeti Tablo 2 'de gösterilmektedir.

\section{TARTIŞMA}

Önceki araştırmalar, ergenlerin ve genç yetişkinlerin interneti, eğlence ya da arkadaşlarla ve yabancılarla iletişim kurmak gibi farklı amaçlar için diğer yaş gruplarından daha sık kullandıklarını göstermiştir. $\mathrm{Bu}$ nedenle, bu kullanıcı grubunun internet bağımlılı̆̆1 ve psikososyal sorunlara karş1 daha savunmasiz durumda oldukları kabul edilmelidir. ${ }^{10}$ Batıgün ve Kılıç 2011 yılında Ankara ve İstanbul illerinde öğrenim gören 1198 üniversite öğrencisi üzerinde yaptıkları bir araştırma sonucunda, katılımciların \%18,9'unu internet bağımlısı olarak tanımlamışlardır. ${ }^{11}$ 


\begin{tabular}{|c|c|c|}
\hline & Model 1 & Model 2 \\
\hline & OR (95\% C.I.) & OR (95\% C.I.) \\
\hline \multicolumn{3}{|l|}{ Genel } \\
\hline Yaş & $-0,992(0,966-1,018)$ & $0,994(0,968-1.021)$ \\
\hline Cinsiyet & $1,136(0.971-1.329)$ & $1,016(0.864-1,196)$ \\
\hline Eğitim & $1.571(1,342-1,546)^{* *}$ & $1,533(1,304-1,801)^{* *}$ \\
\hline Akademik y1l kayb1 & $1.307(1.105-2.330)^{* *}$ & $1,185(0,997-1,409)$ \\
\hline \multicolumn{3}{|l|}{ Mental sağlık } \\
\hline Depresyon & & $1,799(1,485-2,179)^{* *}$ \\
\hline Anksiyete & & $1,708(1,423-2,050)^{* *}$ \\
\hline \multicolumn{3}{|l|}{ Model istatistikleri } \\
\hline Omnibus $\mathrm{X}^{2}$ & $43,071 \mathrm{p}<0.001$ & $173,553 p<0.001$ \\
\hline Sinıflandırma doğruluk oranı & $\% 65,2$ & $\% 66,7$ \\
\hline
\end{tabular}

Düzce'de üniversite yurdunda yapılmış olan bir başka çalışmada ise bu oran \%56,9 olarak tespit edilmiştir. ${ }^{12}$ Oranlardaki bu farklılıkların sebepleri; çalışmalardaki metodolojik farklılıklar, evrensel bir internet bağımlılığı ölçeğinin belirlenmemiş olması, örneklem kümelerinin sosyodemografik özelliklerinin birbirlerinden çok farklı olmaları ve çalışmaların farklı kanallar üzerinden yapılmış olması olarak yorumlanabilir.

İnternet bağımlılı̆̆ ve cinsiyet ilişskisinin incelendiği Bakken ve arkadaşlarının 2009'da yaptığı epidemiyolojik çalışmada erkeklerde internet bağımlılığının daha fazla oranda görüldüğü bildirilmiştir. ${ }^{13}$ Çalışmamızın bulguları ise bağımlılık yaratan internet kullanımının araştıııldığı bazı çalışmalarda olduğu gibi cinsiyete duyarlı olmadığını göstermişti. ${ }^{14,15}$ İnternetin yaygınlaştığı ilk yıllarda, interneti kullanan erkeklerin oranının kadınlardan daha yüksek olduğu bilinmektedir. İnternetin yaygın kullanımı ile birlikte, bu açığın azalması, kadın ve erkeklerin internet kullanımındaki farklılıkların da azalmasına neden olmuş ve bu fark kaybolmuş olabilir. Bunun yanı sıra eğitim süresi uzunluğu ve akademik başarıda düşüklük gözlenmesi pek çok eğitim ve tıp bilimcinin de benzer şekildeki araştırmalarında gösterdiği gibi internet bağımlılığına eğilim olması ile ilişkiliydi. ${ }^{16-18}$

Regresyon modelinde incelendiği üzere, kişinin daha depresif veya endișeli olmasının internet bağımlılı̆̆ 1 riskinde artışla ilişkili olduğu gözlendi. Yen ve arkadaşlarının çalışmasında psikiyatrik belirtileri ve internet bağımlılığı olan gençlerin, internet bağımlılığı olmayanlara göre daha yüksek psikiyatrik semptomlara sahip oldukları bulunmuştur. ${ }^{19}$ Örneğin Farahani ve arkadaşlarının İran'da yaptıkları çalışmada depresyonun internet bağımlılığını 2,2 kat, anksiyetenin 2,6 kat artırdı ğ1; Gupta ve arkadaşlarının Hindistan'da yaptıkları çalışmada depresyonun 2,6 kat, anksiyetenin 2,3 kat artırdığını; Kitazawa ve arkadaşlarının Japonya'da yaptıkları çalışmada ise depresyonun 2,2 kat, anksiyetenin ise 1,4 kat artırdığını göstermişlerdi. ${ }^{20-}$ ${ }^{22}$ Çalışmamızdaki skorlar da, internet bağımlılığıyla, depresyon ve anksiyete arasında anlamlı ve pozitif bir ilişki olduğunu bildiren gelişmiş ülkelerde yapılan önceki çalışmaların sonuçları ile tutarlıydı. ${ }^{15,23}$

Çalışmamızdaki veriler fakültede eğitim gören, akademik yıl kaybı olan, depresyon veya anksiyete bozukluğu tanısı olan üniversite öğrencilerinin internet bağımlılı̆̆ çok risk altında olduklarını göstermiştir.

İnternet bağımlılı̆̆ ile mental sağlık arasındaki nedensellik henüz tam çözümlenememiş olsa da her alan ve toplulukta internet kullanımının yaygınlaşmasıyla birlikte özellikle gençler riskli populasyonda yer aldığından, birinci basamakta sıklıkla karşılaşabileceğimiz depresyon veya anksiyete bozukluğu mevcut olan gençlerin takibinde internet bağımlılığının da göz önünde bulundurulması önem taşımaktadır. ${ }^{24}$

\section{SONUC}

Sonuç olarak bu çalışmada, internet bağımlılı̆̆ının depresyon ve anksiyete gibi ruhsal bozukluklarla ilişkili olduğu saptandı. Çalı̧̧mamız internet bağımlılığı konusunda öncelikle geniş bir örneklem üzerinde $(\mathrm{N}=3064)$ gerçekleştirilmiş olup, hem bağımlılık oranları, hem de ilgili sosyodemografik ve psikolojik değişkenler hakkında bilgiler içermektedir. Çok merkezli ve geniş ölçekli çalışmalar bu konunun daha geniş bir perspektifte incelenmesine olanak sağlayacaktır. 


\section{KAYNAKLAR}

1. International Telecommunication Union $U$. Country classifications. Available at: https://www.itu.int/en/ITU-

D/Statistics/Pages/definitions/regions.aspx. Accessed April 16, 2019.

2. TUİK. Türkiye İstatistik Kurumu, hanehalkı bilişim teknolojileri kullanım araştırması, 2018. Available at: http://www.tuik.gov.tr/PreHaberBultenleri.do?i $\mathrm{d}=27819$. Accessed April 16, 2019.

3. Sim T, Gentile DA, Bricolo F, Serpelloni G, Gulamoydeen F. A conceptual review of research on the pathological use of computers, video games, and the internet. Int $\mathrm{J}$ Ment Health Addict. 2012;10(5):748-769.

4. Shaw M, Black DW. Internet addiction. CNS Drugs. 2008;22(5):353-365.

5. King DL, Delfabbro PH. Internet gaming disorder treatment: A review of definitions of diagnosis and treatment outcome. J Clin Psychol. 2014;70(10):942-955.

6. Durkee T, Carli V, Floderus B, et al. Pathological internet use and risk-behaviors among European adolescents. Int J Environ Res Public Health. 2016;13(3):294.

7. Suler JR. To get what you need: healthy and pathological internet use. CyberPsychology Behav. 1999;2(5):385-393.

8. Ögel K, Karadă̆ F, Evren C, Gürol DT. Bağımlılık Profil İndeksi (BAPİ) Uygulama Rehberi. Istanbul: Yeniden Yayınlar1; 2012 p:13-27.

9. Ögel K, Evren C, Karadağ F, Tamar Gürol D. Bağımlılık Profil Indeksi'nin (BAPI) geliştirilmesi, geçerlik ve güvenilirliği. Türk Psikiyatri Dergisi. 2012;23:264-273

10. Valkenburg PM, Peter J. Online communication among adolescents: An itegrated model of its attraction, opportunities, and risks. J Adolesc Heal. 2011;48(2):121-127.

11. Durak Batıgün A, Kılıç N. İnternet bağımlılı̆̆ ile kişilik özellikleri, sosyal destek, psikolojik belirtiler ve bazı sosyo-demografik değişkenler arasındaki ilişkiler. Turkish J Psychol. 2011;26(67):1-10.

12. Senih Mayda A, Yilmaz M, Bolu F, et al. Bir öğrenci yurdunda kalan üniversite öğrencilerindeki internet bağımlılığı ve Beck depresyon ölçeği arasındaki ilişki. Konuralp Tip Derg. 2015;7(1):6-14.

13. Bakken IJ, Wenzel HG, Götestam KG, Johansson A, Øren A. Internet addiction among Norwegian adults: A stratified probability sample study. Scand J Psychol. 2009;50(2):121-127.

14. Ha Y-M, Hwang WJ. Gender differences in internet addiction associated with psychological health indicators among adolescents using a national web-based survey. Int J Ment Health Addict. 2014;12(5):660-669.

15. Smahel D, Brown BB, Blinka L. Associations between online friendship and internet addiction among adolescents and emerging adults. Dev Psychol. 2012;48(2):381-388.

16. Huang RL, Lu Z, Liu JJ, et al. Features and predictors of problematic internet use in Chinese college students. Behav Inf Technol. 2009;28(5):485-490.

17. İskender $M$, Akin A. Self-Compassion and Internet Addiction. TOJET: The Turkish Online Journal of Educational Technology. 2011;10:215-221.

18. Eldeleklioğlu J, Vural M. Predictive effects of academic achievement, internet use duration, loneliness and shyness on internet addiction. Hacettepe Üniversitesi Eğitim Fakültesi Derg. 2013;28(28-1):141-152.

19. Yen J, Ko C, Yen C, Chen S, Chung W, Chen C. Psychiatric symptoms in adolescents with Internet addiction: Comparison with substance use. Psychiatry Clin Neurosci. 2008;62(1):916.

20. Farahani M, Alavi SS, Mirzamani Bafghi M, Esmaili Alamuti S, Taghavi Z, Mohammadi M. Psychological factors including demographic features, mental illnesses, and personality disorders as predictors in internet addiction disorder. Iran J Psychiatry. 2018;13(2):103110.

21. Gupta A, Khan AM, Rajoura OP, Srivastava S. Internet addiction and its mental health correlates among undergraduate college students of a university in North India. J Fam Med Prim care. 2018;7(4):721-727.

22. Kitazawa M, Yoshimura M, Murata M, et al. Associations between problematic internet use and psychiatric symptoms among university students in Japan. Psychiatry Clin Neurosci. 2018;72(7):531-539.

23. Weinstein A, Dorani D, Elhadif R, Bukovza Y, Yarmulnik A. Internet addiction is associated with social anxiety in young adults. Ann Clin Psychiatry. 2015;27(1):2-7.

24. Ko C-H, Yen J-Y, Yen C-F, Chen C-S, Chen $\mathrm{C}-\mathrm{C}$. The association between internet addiction and psychiatric disorder: A review of the literature. Eur Psychiatry. 2012;27(1):1-8. 